\title{
NEOLIBERALISMO COMO IDEOLOGIA: UMA REFLEXÃO SOBRE A SUA REPRODUÇÃO NA VIDA COTIDIANA A PARTIR DE HENRI LEFEBVRE
}

Luiza Damboriarena ${ }^{1}$

\section{Resumo}

O argumento deste ensaio é que a obra de Henri Lefebvre (1991a, 1991b, 2002, 2014) sobre a vida cotidiana auxilia na compreensão da ideologia neoliberal em uma de suas manifestações mais importantes: o cotidiano. Com base nas proposições de Puello-Socarrás (2008) e Harvey (2013), defendo que o neoliberalismo é uma ideologia que invade todas as esferas da vida social, organizando, inclusive, a vida cotidiana à sua lógica. Porém, apesar desses autores o conceberem como um ideário multidimensional de amplo alcance, se referem, majoritariamente, aos grandes acontecimentos e às implicações macroestruturais, sem examinar sua influência na experiência vivida, isto é, sem abranger o que o autor chama de fenômeno humano total.

Palavras-chave: Neoliberalismo. Ideologia e Vida Cotidiana.

\section{NEOLIBERALISM AS IDEOLOGY: A REFLECTION ON ITS REPRODUCTION IN EVERYDAY LIFE BASED ON HENRI LEFEBVRE}

\begin{abstract}
The argument of this essay is that Henri Lefebvre' (1991a, 1991b, 2002, 2014) about everyday life allows the understanding of neoliberal ideology in one of its most important manifestations: everyday life. Based in PuelloSocarrás (2008) and Harvey (2013), I argue that neoliberalism is an ideology that invades all spheres of social life, even organizing daily life according to its logic. However, although these authors conceive it as a multidimensional and wide range ideology, they refer mainly to major events and macro-structural implications, without examining their influence on the lived experience, that is, without reach what the author calls total human phenomena.
\end{abstract}

Keywords: Neoliberalism. Ideology and Everyday Life.

\footnotetext{
1 Mestre e Doutoranda em Administração - PPGA-UFRGS. E.mail: luizadamboriarena@hotmail.com Revista Brasileira de Estudos Organizacionais - v. 3. n. 1, p. 63-76, jun.2016, eISSN: 2447-4851 Doi 10.21583/2447-4851.rbeo.2016.v3n1.72 Sociedade Brasileira de Estudos Organizacionais
} 


\section{NEOLIBERALISMO COMO IDEOLOGÍA: UNA REFLEXIÓN SOBRE SU REPRODUCCIÓN EN LA VIDA COTIDIANA CON BASE EN HENRI LEFEBVRE}

\section{Resumen}

El argumento de ese ensayo es que obra de Henri Lefebvre (1991a, 1991b, 2002, 2014) acerca de la vida cotidiana permite comprender la ideología neoliberal en una de sus manifestaciones más importantes: el cotidiano. Con base en Puello-Socarrás (2008) y Harvey (2013), argumento que el neoliberalismo es una ideología que invade todas las esferas de la vida social, organizando, incluso, la vida cotidiana a su lógica. Sin embargo, a pesar de esos autores concibieren el neoliberalismo como un ideario multidimensional de amplio alcance, se refieren, principalmente, a los grandes eventos y las implicaciones macro-estructurales sin examinar su influencia sobre la experiencia vivida, es decir, sin incluir lo que el autor llama de fenómeno humano total.

Palabras-clave: Neoliberalismo. Ideología y Vida Cotidiana.

A proposta desse texto é ensaiar o argumento de que a obra de Henri Lefebvre (1991a, 1991b, 2002, 2014) sobre a vida cotidiana auxilia na compreensão da ideologia neoliberal em uma de suas manifestações mais importantes: o cotidiano. Os autores referenciados para analisar o neoliberalismo - Puello-Socarrás (2008) e Harvey (2013), apesar de o conceberem como um ideário multidimensional de amplo alcance, se referem, majoritariamente, aos grandes acontecimentos e às implicações macroestruturais, sem examinar sua influência na experiência vivida. Para prosseguir, descrevo as respectivas concepções de neoliberalismo, segundo esses autores. Após, explico o que constitui o estudo da vida cotidiana, a partir da obra 'A crítica da vida cotidiana' de Lefebvre, escrita em 3 volumes, (1947-1958-1981), além do livro 'A crítica da vida cotidiana no mundo moderno' (1968). Ao tratar a transição entre os diferentes volumes e as mudanças da época, faço uma relação com o surgimento do ideário neoliberal e suas implicações na organização do cotidiano, tentando, ao final, demonstrar como dessa dimensão é fundamental para compreender a ideologia neoliberal na totalidade.

De acordo com Puello-Socarrás (2008, p. 17), o neoliberalismo é uma prática constitutiva do capitalismo contemporâneo que baseia-se na sujeição e subordinação ao mercado como meio de produção e reprodução social em sentido amplo. Ou seja, “[...] uma prática discursiva construída, 
constituída e realizada por uma dialética específica, contínua e constante entre teoria e práxis". Representa, também, um amplo projeto sóciopolítico de classe, de longo prazo, que perpassa todas as dimensões sociais.

Harvey (2005, p. 2), por sua vez, considera o neoliberalismo como uma teoria das práticas político-econômicas que propõe que o bem-estar humano pode ser melhor promovido liberando-se as liberdades e capacidades empreendedoras individuais no âmbito de uma estrutura institucional caracterizada por sólidos direitos a propriedade privada, livres mercados e livre comércio.

É com base na visão desses autores que defendo que o neoliberalismo é uma ideologia que invade todas as esferas da vida social, organizando, inclusive, a vida cotidiana à sua lógica. Assim, para alcançar as suas múltiplas dimensões, determinações e contradições, é fundamental compreender o cotidiano, no qual a existência social se realiza.

Porém, antes de adentrar nesse tema, é necessário definir o entendimento de ideologia, fundamental para esse estudo. $\mathrm{Na}$ visão de Lefebvre (1991a, p. 148), as ideologias "são máscaras que blindam os homens da sua vida real", isto é, mistificações capazes de fazer os homens aceitarem determinadas ilusões e aparências, que se tornam efetivas na medida em que passam a ser reproduzidas por eles mesmos. Dessa forma, a ideologia é uma ilusão eficiente, que não se reduz a falsa consciência, ela é concreta e serve como meio de ação. Para o autor, as pessoas, em geral, não sabem direito como vivem, isto é, tem um inadequado conhecimento das suas próprias necessidades, aspirações e atitudes. Se veem e agem pelos valores ideológicos. Ainda assim, a consciência depende da vida real, ou seja, "os homens são o que fazem e pensam de acordo com o que fazem". Eles são ignorantes sobre o que fazem e o que são porque "[...] seu próprio trabalho e realidade estão além do seu entendimento". Os seres humanos, dessa forma, vivenciam o mundo como algo alheio e estranho:

\footnotetext{
Em termos mais gerais, [...] a atividade humana gera relações que se disfarçam de coisas. Estas coisas e a forma como funcionam estão além do alcance da ação ou da consciência, e permitem interpretações, hipóteses e explicações que são tão distantes da realidade e da verdade quanto elas poderiam ser: ideologias (LEFEBVRE, 1991a, p. 179).
}

Mas, afinal, em que consiste o estudo da vida cotidiana? Segundo Lefebvre (1991b, p. 33), trata-se de uma vasta pesquisa sobre fatos subestimados pelos filósofos ou separados arbitrariamente pelas ciências sociais. Para o autor, o cotidiano não se reduz à soma de atos isolados como trabalhar, comer, dormir, vestir-se, mas a um encadeamento de acontecimentos interligados que se desdobram em um espaço e tempo social. Lefebvre (1991a) atribui ao cotidiano uma significação mais 
relevante. Ele o vê como um solo fértil que, mesmo sem flores ou árvores, comporta as raízes abaixo, ou seja, riquezas e segredos não revelados. Nesse sentido, a proposta é revelar a imensa riqueza presente nos fatos mais humildes da vida, escondida sob a aparente pobreza do cotidiano, pois é sobre esse plano 'inferior', "[...] sobre a larga base da cotidianidade que repousa o edifício piramidal da sociedade" (LEFEBVRE, 1991b, p. 66).

O cotidiano, ao abranger todas as atividades e relações humanas, seja de trabalho, lazer, vida privada e vida pública, é uma dimensão fundamental para entender a sociedade, a sua estrutura, seu modo de funcionamento, seus dilemas e conflitos. É nele que a vida acontece e que as relações sociais se reproduzem, ou, nas palavras de Lefebvre (1991b, p.37), "é nele que se situa o centro real da práxis". A vida cotidiana é, também, produto do modo de produção. "O modo de produção, como produtor, e a vida cotidiana, como produto, iluminam um ao outro". Por isso, o cotidiano só é compreensível se pensado na totalidade. Logo, o objetivo não é saber se ele tem ou não mudado, ou prever o que está sendo alterado ou consolidado, mas, sim, se a crítica da vida cotidiana pode servir como um meio para o conhecimento das relações sociais que produzem e são produtoras da e na totalidade (LEFEBVRE, 2014, p. 687).

O que a crítica da vida cotidiana busca, então, é a expansão das possibilidades de apropriação do cotidiano, de seus sentidos e de suas significações enquanto experiência social, através de um projeto político e intelectual. A tarefa inicial, de acordo com o autor, é apreender e reagrupar, de maneira não arbitrária, fatos aparentemente insignificantes, segundo conceitos e segundo uma teoria, captando a essência e lhes dando um sentido, para, então, ser capaz de enxergar as contradições. Ou seja, trata-se de definir a sua constituição, transformações e perspectivas, detendo e ordenando, entre a variedade dos fatos, alguma coisa de essencial. Além disso, para Lefebvre (1991a), estudar o cotidiano corresponde a explorá-lo pelas diferentes dimensões em que ele é e se dá. Essas três dimensões são o trabalho, a família e o lazer. Postas em relação, formam uma unidade, um sistema dialético pelo qual seria possível reconstruir historicamente um quadro real do homem em certo estágio do seu desenvolvimento, de alienação e desalienação, ou seja, pensar o homem em sua totalidade. Dessa forma, a vida cotidiana está imbricada com essas três dimensões que marcam a existência concreta dos homens. Ela é o ponto de encontro, a ligação, o terreno comum.

O estudo da vida cotidiana também tem interesse por compreender como a sociedade reitera e repete tendências e como se transforma, visto que não há repetição do velho sem uma certa criação do novo, produto sem obra. A possibilidade de mudança, para Lefebvre (1991a), está centrada na contradição inerente que se manifesta na relação de conflito entre o racional e o irracional. Ele busca extrair o vivo, o novo, o positivo, desde os elementos negativos: as alienações. Sua referência inicial é a 
experiência vivida, isto é, a vida real como ponto de partida, voltando-se, especialmente, para o que pode ser transformado em termos qualitativos.

Portanto, para Lefebvre (2002, p. 17), estudar o cotidiano é a esperança de transformá-lo, "descobrir o que precisa e pode mudar e ser transformado na vida das pessoas". Contudo, para que essas possibilidades possam vir-a-ser, é necessária uma crítica da vida cotidiana que só tem sentido se contribuir para mudar a realidade que critica. Por isso, seu projeto inicial tinha como palavra de ordem: "mudar a vida".

$\mathrm{O}$ primeiro volume, a Introduction à la critique de la vie quotidienne, escrito em 1946 na França, surge no contexto pós Segunda Guerra Mundial, em uma Europa devastada em busca da sua reconstrução. “Naquele momento se reconstituía na França a vida econômica e social. Muitos acreditavam estar construindo uma outra sociedade, enquanto trabalhavam para restabelecer, um pouco modificadas, as antigas relações sociais" (LEFEBVRE, 1991b, p. 37). Lefebvre (1991a) acreditava, naquele momento, na possibilidade de uma regeneração da sociedade pela atividade produtiva, quando o homem se definia, ainda, pelo seu papel produtor e criador, atrelada ao papel ativo da classe operária, naquele processo, e ao otimismo das ideias marxistas.

Para o autor, o caráter ambíguo das relações cotidianas, naquele momento, era decorrente da situação contraditória do proletariado no interior da sociedade capitalista. A classe operária, através de sua privação de riqueza e poder, ao mergulhar no cotidiano, seria capaz de negá-lo e transformá-lo, através do conhecimento, enquanto a burguesia teria a ilusão de poder escapá-lo, vivendo como um perpétuo domingo da vida. Assim, a aposta estava depositada na capacidade da classe operária liderar o processo de reconstrução da vida social, mas a solução revolucionária para as contradições econômicas e sociais só seria possível quando os homens não aceitassem mais continuar a viver como antes, ou seja, recusassem o cotidiano e o reorganizassem para dissolvê-lo e transformálo. Mas afinal o que aconteceu?

Enquanto Lefebvre escrevia o primeiro volume de A crítica da vida cotidiana (1946), um novo projeto sociopolítico e econômico, fundamentado na soberania do mercado, era planejado. De acordo com Anderson (1995), logo depois da Segunda Guerra Mundial, na Europa e na América do Norte, eram formadas as bases do neoliberalismo como uma reação teórica e política enérgica em contraposição ao Estado intervencionista e de Bem-Estar, tendo como texto fundador 'O Caminho da Servidão', de Friedrich Hayek, escrito em 1944. Passados três anos, Hayek convocou aqueles com os quais compartilhava ideias para uma reunião na estação de Mont Pèlerin, na Suíça. Foi, ali, fundada a Sociedade Mont Pèlerin, com o objetivo de combater o keynesianismo e o solidarismo dominantes na Europa naquele período, e montar as bases para um capitalismo livre de regras, sob o argumento de que a política igualitária do período de Bem-Estar destruía a liberdade dos cidadãos e a força da 
concorrência, fundamental para a prosperidade coletiva, e de que a desigualdade é um valor positivo.

De acordo com Harvey (2013), esse projeto atacava todas as formas de solidariedade social prejudiciais à livre competição, além de derrubar ou reverter os compromissos do Estado de Bem-Estar Social, juntamente com a privatização de empresas públicas, redução de impostos, promoção do empreendedorismo, a fim de criar um ambiente favorável aos negócios que estimulasse um forte fluxo de investimentos. Logo, todo tipo de solidariedade social deveria ser dissolvido em favor do individualismo e da propriedade privada, sob a justificativa de que o mercado permitiria o exercício pleno das liberdades individuais.

Entretanto, as ideias neoliberais passaram a ganhar força somente com a crise do modelo econômico do pós-guerra, em 1973, quando o mundo capitalista avançado entrou numa longa e profunda recessão, com baixas taxas de crescimento e altas taxas de inflação. Essas ideias defendiam que a raiz dos problemas estava no poder excessivo dos sindicatos, prejudicial à acumulação capitalista devido a suas reivindicações por melhores salários e ao aumento de investimento estatal em gastos sociais, o que, em tese, prejudicaria os níveis indispensáveis de lucros das empresas, desencadeando processos inflacionários que culminariam em uma crise generalizada das economias de mercado. A solução então proclamada estava em manter um Estado forte capaz de reprimir as aspirações do trabalho e os movimentos populares, enfraquecer os sindicatos, restringir os gastos sociais, restaurar as taxas de desemprego para formação de um exército de reserva, além de medidas de austeridade para garantir a estabilidade monetária.

Foi assim que, de acordo com Harvey (2013, p. 27), o mundo capitalista mergulhou na neoliberalização como um “[...] potencial antídoto para ameaças à ordem social capitalista e como solução para as mazelas do capitalismo". Embora com idas e vindas, experimentos caóticos, adesões tanto voluntárias como coercitivas, essa doutrina se consolidou, em nível global, com a articulação do "Consenso de Washington", que representou um marco nas orientações políticas mundiais, composto por um conjunto de dez medidas formuladas em 1989, passando por sucessivas renovações ao longo do tempo (Consenso Revisado, Ampliado e Pós-Washington).

Para Harvey (2013, p. 17), a força do neoliberalismo decorre de sua capacidade de propor um aparato conceitual convincente, sedutor e inquestionável, valendo-se dos ideais de dignidade e liberdade individual, que se tornaram os valores centrais da civilização, sob o “[...] pressuposto de que as liberdades individuais são garantidas pela liberdade de mercado e de comércio". Assim, o neoliberalismo se tornou a ideologia dominante, com uma ampla e poderosa influência sobre os modos de pensamento e ação, modificando as maneiras cotidianas dos indivíduos interpretarem, viverem e compreenderem a sociedade. “O efeito disso em muitas partes 
do mundo foi vê-lo cada vez mais como uma maneira necessária e até completamente natural de regular a ordem social" (HARVEY, 2013, p. 50).

Segundo Harvey (2013, p. 195), o que importa, nesse ideário, é que não sejam impostas restrições à acumulação de capital e, aonde não houverem mercados, eles devem ser criados pelo Estado. Nesse sentido, viver sob o neoliberalismo implica uma aceitação ou submissão a essa ordem: "aceitar o regime neoliberal equivale a aceitar que a única alternativa é viver sob um regime de interminável acumulação do capital e crescimento econômico, quaisquer que sejam as consequências sociais, ecológicas ou políticas". Harvey (2007) também afirma que o neoliberalismo se espalhou pelo mundo como uma poderosa arma de reforma institucional e ajustamento discursivo, tornando-se o padrão de regulação global do qual ninguém sai imune.

Para Puello-Socarrás (2013a, p. 4), essa é a etapa capitalista que mais aprofunda e intensifica "[...] as lógicas e contradições inerentes à reprodução e acumulação incessante do capital", como "[...] a exploração econômica, a dominação política, a opressão social e a alienação ideológica". Além disso, segundo Harvey (2013), esse ideário, defensor do sacrossanto direito de propriedade e lucro, representa um instrumento de recuperação do poder das elites econômicas. "Embora bem disfarçada, nós convivemos com a completa criação de uma sofisticada luta de classes por parte dos estratos superiores na sociedade para restaurar ou [...] para construir um poder de classe incontestável" (HARVEY, 2007, p. 26).

Mesmo que não tenha acompanhado todo o movimento do neoliberalismo, Lefebvre (1991b, 2014) descreveu, nos volumes seguintes do primeiro, uma transformação no cotidiano, que envolveu seu empobrecimento, manipulação e passividade. Segundo ele, o cotidiano antes esquecido e subestimado, um espaço-tempo abandonado, livre para as iniciativas sociais, perdeu o seu caráter trágico e o espírito de crítica pela crença na satisfação, liberdade e transparência que esse novo contexto prometia. Ocorreu, além disso, um desvio da capacidade criadora, que foi substituída por "[...] uma passividade contemplativa, por um consumo devorador de signos, de espetáculos, de produtos, mas também de obras, as obras do passado".

Segundo o autor,

na forma atual, o mundo deriva da extensão do mercado e da mercadoria em nível mundial, em um processo desigual que, no entanto, tem deixado de lado toda a resistência, o que não significa que os movimentos populares desapareceram, mas que o mundo do mercado existe e exerce uma pressão forte em todos países.

Assim, para Lefebvre (2014, p. 755), o problema mudou. Deriva não de uma escassez de material ou ignorância sobre vida cotidiana, e sim de uma abundância de informação e excesso de conhecimento positivo que assegure que todos saibam o que acontece e deve ser feito. "Muito mais do 
que em 1960, toda a gente sabe como viver em 1981". Eles sabem graças ao conhecimento que não se origina neles, que eles assimilam e aplicam aos seus casos individuais, às suas vidas, de acordo com um modelo desenvolvido e difundido para eles. O cotidiano, antes esquecido, passou a ter espaço nos jornais, na literatura, mas a dimensão crítica permaneceu obscura ou banida.

Segundo Lefebvre (1991b, p. 68), "o cotidiano, no mundo moderno, deixou de ser sujeito (rico de subjetividade possível) para se tornar objeto (objeto da organização social). Enquanto objeto, longe de desaparecer ele, ao contrário, se reafirma e se consolida". Nesse contexto, "a alienação adquire um sentido profundo. Ela afasta o cotidiano da sua riqueza. Dissimula o lugar da produção e da criação, humilhando-o e recobrindo-o com o falso esplendor das ideologias" (LEFEBVRE, 1991b, p. 40). Longe das possibilidades, o cotidiano é marcado por nada mais que repetição, miséria e desencanto, sendo assim "o sentido da vida é a vida desprovida de sentido, sem história, a cotidianidade perfeita", restando como alternativa negá-la ou fugir assim que for possível (LEFEBVRE, 1991b, p. 133).

De acordo com Lefebvre (1991b, 2014), as transformações que empobreceram o cotidiano, que o organizaram no ritmo do mercado, se deram pela via do consumo, da publicidade, dos métodos de planejamento, da urbanização massiva, do progresso técnico etc. Segundo o autor, esse novo cotidiano é marcado pela prevalência do valor de troca e de equivalência, do quantitativo pelo qualitativo, que se tornaram dominantes e passaram a restringir a singularidade da experiência cotidiana; pela substituição dos processos e tempos rítmicos pela linearidade; pela desvalorização da capacidade criadora do trabalho; pela supressão do papel ativo da classe trabalhadora; pela cientificidade e pelo mito da transparência, mergulhados na crença de estar livre das ideologias, ou melhor, pela ideologia do fim da ideologia. Assim, a alienação se intensificou ao longo desse processo, “[...] conseguiu-se afastar e até apagar a consciência da alienação, acrescentando alienações novas às antigas" (LEFEBVRE, 1991b, p. 64).

Hoje as ideologias mudaram, elas têm nome: funcionalismo, formalismo, estruturalismo, operacionalismo, cientificismo. Elas se apresentam como não-ideologias, misturando-se mais sutilmente que antes ao imaginário. Elas mascaram o fato fundamental, isto é, o fundamento de fato: tudo importa, tudo tem peso sobre a cotidianidade, que revela o "tudo" em questão (ou seja, que sua análise crítica mostra o "tudo" colocando-o em questão) (LEFEBVRE, 1991b, p. 81).

Lefebvre (1991b, p. 64) designa esse momento como sociedade burocrática de consumo dirigido. Umas das principais marcas desse período é a substituição da imagem do homem ativo pela imagem do 
consumidor "[...] como razão de felicidade, como racionalidade suprema, como identidade do real com o ideal (do eu ou sujeito individual, que vive e que age com o seu objetivo)"; também é marcada pelo advento da classe média, que torna os limites de classe complexos e fluídos; pela substituição da noção de cidadão pela de usuário; além da prevalência da cotidianidade sobre o cotidiano (LEFEBVRE, 2014).

A vida cotidiana, como produto do modo de produção, é organizada por uma ação combinada e planejada, ou seja, por uma estratégia de classe pela qual alguns poucos, no alto da escala hierárquica, se beneficiam ao transcenderem, em aparência, a cotidianidade, enquanto os demais, na esfera mais baixa desse plano, suportam o peso, vivendo na ambiguidade "satisfação-frustração", até o momento que leve a um conflito. Segundo ele, "forças políticas e formas sociais convergem na mesma direção: consolidar o cotidiano, estruturá-lo, torná-lo funcional" (LEFEBVRE, 1991b, p. 73).

Tornar o cotidiano funcional, no neoliberalismo, significa voltá-lo para o mercado, ou seja, inserir os princípios do individualismo e da competição em todas as atividades e relações sociais. Isso pode ser demonstrado pela ação das ideologias complementares do gerencialismo e do empreendedorismo, que levam a lógica dos negócios para todo tipo de prática social, abordados mais adiante.

No último volume, De la modernité au modernisme, Pour une métaphilosophie du quotidien, publicado em 1981, Lefebvre (2014) já admitia que a vida cotidiana adentrava nos circuitos do mercado e nas práticas de gestão, tornando-se funcional ao modo de produção. Segundo ele, havia uma tendência geral e contínua de administrar a vida cotidiana como uma empresa, isto é, a empresa como figura dominante da sociedade. De acordo com o autor, a grande empresa moderna não se contenta em ser uma unidade econômica, nem de fazer pressão sobre a política, ela invade a prática social e propõe à sociedade inteira sua racionalidade como modelo de organização e de gestão (LEFEBVRE, 1991b, p. 75).

Lefebvre (2014) antecedia, então, uma tendência que se concretizou, ou seja, a difusão da racionalidade empresarial para além do campo econômico, invadindo a esfera política e a vida privada como a forma mais eficiente, se não a única, de sobreviver em uma sociedade neoliberal. A empresa passa a ser a organização central e característica da sociedade moderna, e a sua forma de administração um modelo a ser seguido como fórmula de sucesso.

Entre os anos 1980 e 1990, valores, símbolos, técnicas e crenças do mundo dos negócios foram conduzidos da esfera privada para a esfera pública, influenciados pela Nova Administração Pública (NAP) e pelo movimento Reinventando o Governo de Osborne e Gaebler (1992). Essas doutrinas atacavam as organizações burocráticas, supostamente incompatíveis com o capitalismo contemporâneo, em defesa de instituições eficientes, flexíveis e produtivas, o que contribuiu para 
decorrentes reformas dos aparelhos de Estado, a fim de construir uma governança neoliberal - empreendedora (PUELLO-SOCARRAS, 2008a).

Esse processo implicou na desvinculação do público do estatal, formando um espaço público-privado ou público não-estatal essencialmente mercantil, isto é, "um locus natural do empreendimento", uma "terceira via", que supera a polaridade entre Estado e mercado, atuando agora como dimensões compatíveis e complementares (PUELLOSOCARRAS, 2008a, p. 23).

Essa nova forma de governo, orientada para resultados, concebe o cidadão como cliente, como julgador do próprio bem-estar e do que é melhor para si, tendo sua ação limitada, isento de muitas obrigações, na medida que a iniciativa individual assume a própria responsabilidade e o mercado passa a ser a fonte de seus direitos, mediante uma situação de competitividade assegurada pelo Estado. Assim, a dimensão pública passa a ser desestatizada, mercantilizada e coordenada pelo mercado, que irá ditar os padrões das organizações e as regras de funcionamento social com a subsunção do Estado (PUELLO-SOCARRAS, 2008a, p. 114).

De acordo com Lefebvre (2014), que analisava esse processo nos seus primórdios, em 1981, o problema começa antes, quando o Estado alega ser um Estado de serviço e não um Estado político. Tem-se, assim, um Estado com um fim nele mesmo e não um meio, um instrumento a serviço da sociedade. Seu aparato organiza nada mais que o cotidiano e o peso das suas instituições se coloca sobre ele. Assim, a degradação da vida cívica ocorre no cotidiano, facilitando a tarefa de quem administra a vida a partir de cima, por meio de instituições e serviços.

Lefebvre (2014) alega que o cidadão perde o poder de protesto, de restaurar o valor de uso subordinado ao valor de troca, e tem seus direitos desvalorizados, se não suprimidos. Ele tende a desaparecer em face do usuário, que se torna um mero habitante, ou seja, mistificado. Os indivíduos não se percebem politicamente. Sua relação com o Estado vai se perdendo. Ademais, as relações com o Estado e a política, que parecem obscurecidas, são, na verdade, objetivamente intensificadas, uma vez que os políticos usam o cotidiano como uma base e uma ferramenta.

No neoliberalismo, portanto, na medida que a esfera pública passa a ser desestatizada, e que o Estado se volta para o mercado, para resultados e para os cidadãos como clientes, estes são incentivados a cuidarem de si, a assumirem os próprios riscos, já que tudo deve ser conquistado constantemente no e pelo mercado. Assim, a alternativa para sobreviver em um sistema que prega o individualismo e faz da concorrência uma justa competição centra-se na iniciativa designada de empreendedorismo, pela qual os indivíduos são levados a atuar e manter relações como se fossem empresas, assumindo a própria responsabilidade, associado a um discurso sedutor de sucesso, liberdade e autonomia.

Para prosseguir com o tema do empreendedorismo é preciso compreender, antes, a evolução do pensamento neoliberal. Segundo 
Puello-Socarrás (2008a), o pensamento neoliberal sofreu influência de cinco diferentes correntes: Escola Neoclássica Anglo-Americana; Escola Neoclássica Europeia Continental ou Escola Neoclássica Austríaca; Neoliberalismo Alemão, que envolve o Ordo-liberalismo, a Escola de Economia Social de Mercado (ESM) e as Escolas de Friburgo e Berlim; e as Sínteses Neoclássico-Keynesianas. Um dos conceitos mais marcantes desse trânsito é a mudança do enfoque do homo economicus (homem econômico), princípio antropológico da corrente anglo-americana, para o homo redemptoris (homem empresário/empreendedor), da corrente austríaca. $\mathrm{O}$ homem econômico (puro) foi, por muito tempo, uma categoria predominante que interpretava o ser humano como um agente econômico racional e calculador, em um cenário de concorrência perfeita. Porém, no final do século $X X$, emergiu uma reivindicação do empreendedorismo como concepção do fenômeno atual.

O homem empresário/empreendedor corresponde a uma exigência epistemológica que permite uma compreensão mais adequada e funcional do capitalismo avançado, sintetizando categorias necessárias para a ideologia neoliberal, como a articulação e interdependência entre as realidades econômica, política e social, que não se consideravam no passado, porém, sem perder os pressupostos basilares do liberalismo contemporâneo (PUELLO-SOCARRAS, 2008a; 2008b).

O homem empreendedor é um empresário de si mesmo, dono de seu próprio capital, que assume os próprios riscos, combina os fatores de produção, explora as possibilidades de inovação e propicia novas combinações entre trabalho e capital. Não é um trabalhador porque não depende da venda da sua força de trabalho. (PUELLO-SOCARRAS, 2008a; 2008b).

A noção de empreendedorismo possibilita a criação de uma classe supostamente imparcial, que neutraliza a relação conflitiva entre capital e trabalho, tornando-se uma terceira via do discurso capitalista, isto é, uma alternativa viável para consolidar a individualização que pauta o ideário neoliberal. Ao delegar ao indivíduo a responsabilidade pela participação no sistema produtivo, o contrato de trabalho é internalizado no trabalhador, bem como o papel de proteção do Estado e os riscos da atividade, transformando o risco suscitado pela insegurança social em um espaço de oportunidades disponíveis para exercitar o espírito competitivo daqueles capazes de empreender. Nessa perspectiva, esse novo tipo societal não altera a estrutura de exploração, dominação e opressão internalizadas em um processo individualizado (PUELLO-SOCARRAS, 2008a; 2008b).

Tudo isso contribui para a desregulamentação do mercado de trabalho, para o enfraquecimento do poder político e de negociação das representações da classe trabalhadora e, principalmente, para a redução do peso relativo dos assalariados, em detrimento do crescimento da informalidade. Contribui, também, para a maior fragmentação da classe 
trabalhadora, que se torna mais frágil e heterogênea, com menor poder de negociação, além de colocar-se em posições opostas e rivais na medida que os ditos empreendedores, por assumirem os riscos e incerteza do mercado, enfraquecem os direitos sociais e a estabilidade dos trabalhadores assalariados.

Segundo Lefebvre (1991a, p.152), o individualismo que marca a sociedade capitalista (e se acentua ainda mais no neoliberalismo) é uma arma de classe que não se limita ao campo das ideias e concepções de mundo, visto que interfere na organização da vida cotidiana. A classe dominante difunde uma noção de sociedade como uma coleção justaposta, fragmentando o corpo social em elementos desconectados, passivos e inertes, isto é, indivíduos no sentido puro da palavra. Para o autor, tal representação "não é mais que ideologia, meio de ação, ilusão eficiente". Além disso, ele também afirma que quando a vida é moldada por tendências individualistas, ela se torna uma vida de privação, privada de realidade, das conexões com o todo, marcada pela alienação.

Lefebvre (2014) também alega que a ideologia presente no cotidiano serve como veículo para as representações e para a manutenção da ordem, através de um conteúdo estável que prolonga as relações de força, dependência, dominação, autoridade e poder, que é tolerável justamente por ser mascarado. Assim, essas relações são ocultas pela ideologia que penetra no senso comum e gera consentimento, se infiltrando em espaços onde, de modo consciente, não seria admitida. Se, despojadas dos véus, elas seriam insuportáveis.

As opressões não reconhecidas e não reconhecíveis assediam a vida dos grupos e os regularizam de acordo com a estratégia geral. A diferença entre a consciência dirigida de fora e aquela que se dirige a si mesma cai por terra, pois o que se mostra como o de dentro não é mais que o de fora investido e transvestido, interiorizado e legitimado (LEFEBVRE, 1991b, p. 158).

É nesse sentido que Lefebvre (1991a, p. 127) argumenta que, para alcançar a realidade, devemos rasgar o véu, o véu que está sempre nascendo e renascendo na vida cotidiana, juntamente com suas implicações mais elevadas ou profundas. Isto é, rasgar o véu de ideologias pelas quais a classe dominante explica a história para si, além de torná-la aceitável para os demais grupos sociais. Para o autor, a superação dessas alienações não pode ser empreendida a partir de algo alheio ao cotidiano. Por isso, nas suas palavras, "o homem será cotidiano ou não será nada".

Lefebvre (1991a, p. 135) também chama atenção para a mudança na análise dos fatos 'significativos', para a soma total dos eventos diários que, segundo ele, corresponde à passagem da aparência para a realidade, do singular para o todo. Somente, a passagem de "[...] aparências glamorosas à essência nos salva de perspectiva ilusórias com que os indivíduos e grupos leram-se ao longo da sua história [...]". Ele adverte que essa soma 
não pode ser reduzida a uma soma aritmética, pois os fatos cotidianos só têm sentido na totalidade. É nessa direção que a crítica da vida cotidiana busca compreender "a vida como ela é" (LEFEBVRE, 1991a, p. 66), sua essência, voltando-se para os encadeamentos dos acontecimentos sociais para compreender a totalidade.

Os autores, aqui referenciados que se propuseram a pensar o neoliberalismo, demonstram o esforço de denunciar as mistificações, de revelar as contradições, de entender a realidade para além das aparências. Porém, como suas formulações se voltam, em geral, para as grandes questões, para os fatos 'significativos', o que não deixa de ser fundamental, não possibilitam que se compreenda a dimensão concreta do neoliberalismo na ação cotidiana. Se o neoliberalismo é ideologia porque tem função prática, a sua compreensão como ideologia exige analisá-lo na prática. Essa possibilidade se abre com o aporte de Lefebvre (1991a, 1991b, $2002,2014)$, isto é, com a crítica da vida cotidiana que possibilita penetrar no conteúdo da vida, ao abranger o que o autor chama de fenômeno humano total.

Assim, para compreender a dimensão concreta do neoliberalismo, na sua totalidade e essência, é preciso ir, imprescindivelmente, ao cotidiano, pois é nele que o conjunto das relações e atividades humanas se expressam e põem em jogo a totalidade do real. Porém, não basta reconhecer a atuação do neoliberalismo na vida cotidiana, é preciso revelar o que está oculto, isto é, denunciar as suas contradições e mistificações, através do conhecimento dos poderes negativos que dirigem esta sociedade, que visam e clamam ser positivos. Para tanto, Lefebvre (2014) não aponta uma definição ou solução acabada, nenhum modelo a ser seguido, apenas uma estrada para explorar e construir, e essa estrada é a vida cotidiana.

\section{Referências}

ANDERSON, Perry. Balanço do Neoliberalismo. In: GENTILI, Pablo; SADER, Emir (Orgs.). Pós-neoliberalismo: as políticas sociais e o Estado democrático. $3^{\text {a }}$ ed. Rio de Janeiro: Paz e Terra, 1996. p. 9-23.

HARVEY, D. O Neoliberalismo: história e implicações. 4. ed. São Paulo: Edições Loyola, 2013.

LEFEBVRE, Henri. Critique of everyday life: Introduction. London: Verso, 1991a, v. 1.

Critique of everyday life: foundations for a sociology of the everyday. London: Verso, 2002, v. 2. 
Critique of daily life. London: Verso, 2014.

A vida cotidiana no mundo moderno. São Paulo: Ática,1991b.

PUELLO-SOCARRÁS, José Francisco. Nueva Gramática del Neo-liberalismo. Itinerarios teóricos, trayectorias intelectuales, claves ideológicas. Bogotá: Universidad Nacional de Colombia, Facultad de Derecho, Ciencias Políticas y Sociales, 2008a.

- ¿Un Nuevo Neo-liberalismo? Emprendimiento y Nueva Administración de lo público. Revista Administración \& Desarrollo. Bogotá: Escuela Superior de Administración Pública, n. 49, 2008b.

Ocho tesis sobre el neoliberalismo (1973-2013). In RAMÍREZ, Hernán. O neoliberalismo Sul-americano em clave transnacional: enraizamento, apogeu e crise. São Leopoldo: Oikos - Unisinos, p. 13-57, 2013 a.

- Breve historia del anti-neoliberalismo. Economía política sudamericana y paradigmas de desarrollo en el siglo XXI. In AA.VV., Anuario de Estudios Políticos Latino americanos, n. 1, Bogotá: Universidad Nacional de Colombia, Maestría en Estudios Políticos Latino americanos, p. 167-186, 2013b.

PUELLO-SOCARRÁS, José Francisco; GUNTURIZ, Maria Angelica. ¿Social-neoliberalismo? Organismos multilaterales, crisis global y programas de transferencia monetaria condicionada. Politica y Cultura. México: Universidad Autónoma Metropolitana - Xochimilco, n. 40, p. 29$54,2013$.

Submetido em: 10/12/2016

Aprovado em: 28/01/2017 
NEOLIBERALISMO COMO IDEOLOGIA: UMA REFLEXÃO SOBRE A SUA REPRODUÇÃO NA VIDA COTIDIANA A PARTIR DE HENRI LEFEBVRE

Luiza Damboriarena 